\title{
Analysis of Causes and Hazards of China's Frequent Hazy Weather
}

\author{
Zhou Jingkun* $^{*}$
}

Department of Law and Public Management, Wuzhou University, Wuzhou, 543002, P.R. China

\begin{abstract}
The focus of haze prevention is how to solve the relationship between social and economic development and the haze prevention. In the current situation where environmental pollution becomes increasingly worse, China needs to enhance the effectiveness of preventing and treating hazy weather. The article first introduces the characteristics of Chinese hazy weather, including a wide range, long duration, mainly occurring in areas with low rain fall, severe pollution, great harm, etc.; then it analyzes the causes of China's frequent hazy weather such as the increased particulate hazards in the air and the increased horizontal static wind and vertical temperature inversion; finally, it points out that China's hazy weather has harmed the health of people, exacerbated the deterioration of the ecological environment, affected social and economic development, etc.
\end{abstract}

Keywords: Causes, characteristics and hazards, China's hazy weather.

\section{INTRODUCTION}

In recent years, with the large-scale industrialization and urbanization of China and the rapid development of industry, transportation, etc., a lot of exhaust gases are discharged into the air, creating favorable conditions for the formation of China's hazy weather, together with the global warming, significant changes have occurred in weather conditions, so the exhaust gases accumulated in the air cannot be diffused in time, resulting in the frequent occurrence of massive hazy weather in China [1]. The disasters of the hazy weather have seriously affected people's daily production and life have brought great challenges to the sustainable development of Chinese society and economy. Many experts and scholars have carried out some exploratory research into the causes and hazards of China's hazy weather. For example, Zhou Tao et al. [2] point out that Beijing's haze concentration is large between 7:00 a.m. and 8:00 a.m. and between 18:00 p.m. and 20:00 p.m. during the rush hours of a day, which indicates that mobile emission sources have become important sources of urban pollution in Beijing. In addition to the significant increase in haze concentration due to short-period setting off of firecrackers during the Spring Festival, Beijing's haze concentration is minimized during holidays, showing that people's activities play a significant leading role in haze concentration; Zhang Liya et al. [3] point out that the causes of China's hazy weather include general atmospheric circulation, extensive economic production mode, irrational energy consumption structure, excessive vehicle emissions, ground dust and so on; Xiao Hongwei [4] points out that the causes of hazy weather include the increased dust emission due to the accelerated industrialization process, irrational coal-based energy consumption structure, urban motor vehicle exhaust, environmental capacity overdraft, insufficient environmental pollution monitoring, etc.; Liu Qiang et al. [5] point out that the causes of hazy weather include that total pollutant discharge is too large, loss of selfpurification function of eco-environment system, the emission standard of air pollutants is too low, etc. Currently, experts and scholars' analysis of China's hazy weather causes still focuses on several aspects, which is not very comprehensive and systematic.

\section{THE CHARACTERISTICS OF CHINA'S HAZY WEATHER}

Haze is composed of both fog and haze. Fog is a kind of weather phenomenon formed by a large number of tiny water droplets or ice crystals floating in the air near the ground where visibility is less than a kilometer, but haze is a phenomenon where air is overall turbid when the visibility is less than 10 kilometers and the relative humidity is less than $80 \%$ due to a large number of very tiny dry dust evenly suspending in the air, which makes the air turbid, the vision blurry and the visibility deteriorated, other than rainfall, dust, smog, snowfall, sandstorm and other reasons [6]. As an atmospheric environment pollution phenomenon that has caused substantial influence upon quite a part of Chinese people's production and life, hazy weather has the following main characteristics.

\subsection{A Wide Range}

The environmental pollution in China becomes more and more serious in recent years, hazy weather involves a fairly broad geographic scope, it is not limited to a single area but it has covered most of China's economically developed regions. Relevant satellite remote sensing data showed on February 22, 2014 that the air pollution in central and eastern China was extremely serious and the contaminated area had reached 1.21 million square kilometers, among which an area of 0.85 million square kilometers had been heavily pol- 


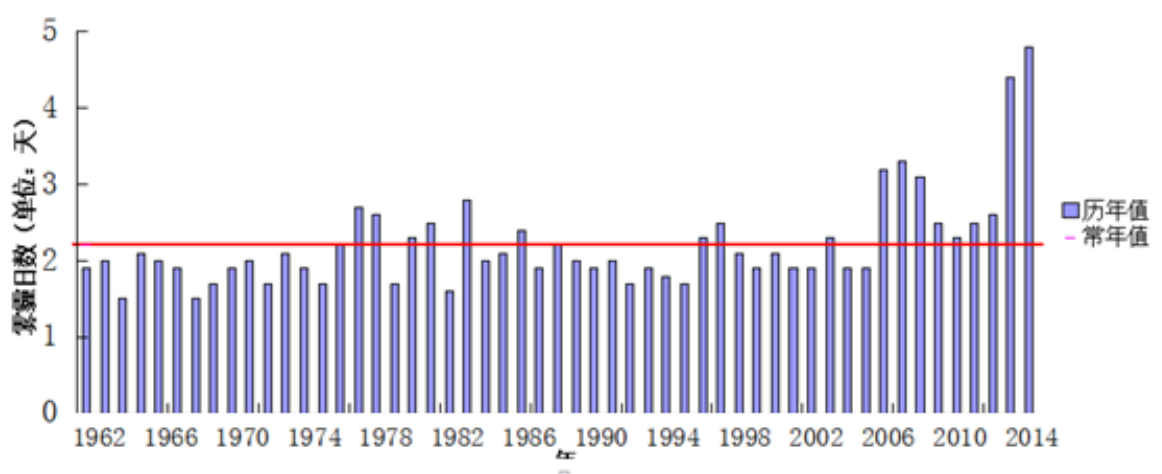

Fig. (1). The average monthly duration of national hazy weather from 1962 to 2014 [7].

luted by hazy weather. For another example, in January 2013, Chinese mainland suffered severe hazy weather for a long period; over one-fourth of China had been affected, including 17 provinces, municipalities and autonomous regions, and about 0.6 billion people had been affected, etc.

\subsection{Long Duration t}

Fig. (1) is a statistical graph showing the average monthly duration of national hazy weather from 1962 to October 2014. Based on the data of the graph, we can see that hazy weather generally lasts about 2 days in each October, but there was an increasing trend since 2005 when hazy weather generally started to last over 2 days. There has even been an unprecedented peak in the past two years. Therefore, we can find that hazy weather not only lasts long, but also shows an increasing trend now. Although its duration fluctuates, the long duration of China's hazy weather, which is an obvious feature, still cannot be hidden.

\subsection{Mainly Occurring in Areas with Low Rainfall}

The main cause of hazy weather is that the particulate hazards suspending in the air cannot be effectively diffused. In addition to the wind, the most effective way to purify the particulate hazards suspending in the air is rain wash because rain can take away the dust in the air. That's why China's hazy weather mostly occurs in the central and eastern regions not in the rainy reason for the past many years, while other heavily polluted areas and cities do not have hazy weather just because these areas have high rainfall and relatively intensive rainfall time. Therefore, most of the areas with frequent occurrence of hazy weather have low rainfall or too long intervals of rainfall time, so they are unable to purify the suspended hazardous particulate matters backlogged in the air.

\subsection{Severe Pollution and Great Harm}

The areas contaminated by hazy weather are mostly heavily polluted. Hazy weather not only causes poor air quality, but also causes extremely serious impact on people's daily life. For example, in January 2013, there was a significant increase in the number of patients in Beijing, Tianjin and Shijiazhuang and most of diseases were caused by poor air quality. The hazy weather also brought a huge challenge to the traffic and the flights of many airlines were canceled due to the hazy weather. The hazy weather on January 13,
2013 caused a 16-car pileup, 2 casualties, etc on Shanghai Kunming Expressway. This shows that the hazy weather not only causes severe pollution, but also great harm to the people.

\section{ANALYSIS OF THE CAUSES OF CHINA'S FRE- QUENT HAZY WEATHER}

As a kind of meteorological weather phenomenon, the causes of China's hazy weather can be divided into the following aspects according to its characteristics, distribution and other circumstances:

\subsection{The Increased Particulate Hazards in the Air}

In the atmosphere, there are already many suspended particles, including dust, sea salt, carbon-based materials, various salts and other categories. The main pollution sources of such particulate hazards include: first, harmful substances discharged by industrial production. High temperatures can accelerate the conversion of sulfur dioxide to sulfate, so the sulfate concentration of the industrial areas in North China in summer will be higher than that in other reasons and areas; second, emissions of coal burning. Large quantities of pollutants will be emitted by industrial coal, heating supply in the north in winter and other coal burning ways and straw burning in rural areas in spring and autumn will cause a significant increase in particulate hazards in the air; third, motor vehicle emissions. There is a significant increase in the number of China's motor vehicles and emissions have been beyond the self-purification capacity of regional environment and become important pollution sources; fourth, engineering construction dust. With the acceleration of Chinese urbanization, construction sites can be seen everywhere and their dust has become one of the important pollution sources. Besides, the sand and dust weather in the western region in spring also provides favorable conditions for the subsequent formation of hazy weather.

\subsection{The Increased Horizontal Static Wind}

With the rapid development of China's urban construction in recent years, higher and higher buildings are built in cities. Wind speed will be significantly reduced due to the blocking of tall buildings and friction when air current passes urban area, leading to the increase in horizontal static wind. This is not conducive to the spread and dilution of pollutants in the atmosphere and it is easy for the pollutants 
to accumulate within cities and near the suburban areas, which provides an opportunity for the formation of hazy weather.

\subsection{The Increased Vertical Temperature Inversion}

An important reason for China's serious environmental pollution is the increased vertical temperature inversion. Vertical temperature inversion is mainly caused by temperature inversion. Temperature inversion may occur if there is a temperature inversion layer in the atmosphere and the temperature of low altitudes may be lower than the temperature of high altitudes. As a result, the pollutants at low altitudes cannot be decontaminated and diffused. The temperature inversion layer hangs in the air just like a large quilt to prevent the spread of pollutants. The moisture particles and particulate matters cannot be diffused when temperature inversion occurs, which can also easily lead to hazy weather.

\section{THE IMPACT OF CHINA'S HAZY WEATHER}

Humans need air to survive and humans need to breathe fresh air every day to maintain body functions. However, the occurrence of hazy weather will cause more and more serious impact on people's daily production and life. Details are as follows:

\subsection{Harming the Health of People}

At present, cancer is the No.1 killer disease for humans and the cancer category directly related to hazy weather is none other than lung cancer. Relevant information shows that although China's smoking rate in public places has shown a declining trend in the past 30 years, the probability of lung cancer has increased sharply, which shows that the probability of lung cancer may be related to haze to some extent. With the increase in the suspended particulate matters in the air, there will be foggy and hazy weather. The bronchi will be damaged if such matters are breathed in from the air and then bacteria will take the opportunity to destroy the original immune system and cause difficulty in breathing. In mild cases, there will be chest distress, shortness of breath, coughing and other phenomena; in serious cases, there will be bronchitis and other diseases. If we continue to allow the bacteria to multiply in our body, canceration may occur, so it cannot be overlooked; in addition, hazy weather will make people feel depressed, which will affect people's mental health and even make them have depression, mania, anxiety and other negative emotions if without timely adjustment.

\subsection{Exacerbating the Deterioration of the Ecological En- vironment}

The occurrence of hazy weather makes regional climate exacerbated, which can easily lead to extreme weather. Extreme weather will cause seasonal meteorological disasters and eventually change the original weather patterns in the season of the region. Under such circumstances, our environment will be chaotic. Injury spots may occur on the leaf surface of plants if pollutant concentration is very high and leaves may even fall; there may be some chronic harm to the plants if pollutant concentration is low, which may make the plants less green or destroy the internal mechanism of the plants and cause quality decline and reduction of output al- though it cannot be found externally. A large number of dust and particles emitted into the air by people in daily production and life can easily lead to increasingly cloudy air, block the sun and result in the reduction of light. Statistics show that in industry-based cities, especially in days with lingering fog and haze, the solar radiation on the ground is $40 \%$ less than usual. Both plants and crops need to grow through photosynthesis and respiration. If the air is heavily polluted, due to continuous haze, the plants will not have good lighting conditions, the yield and quality of the plants and crops will certainly be reduced and people will have their health damaged if always eating them.

\subsection{Affecting Social and Economic Development}

Besides the harm in terms of human health and natural ecosystem, hazy weather also has significant impact on social and economic development. Among others, it is worth noting that the stocks related to haze prevention show a trend of sharp rise. The market value increase of the stocks related to haze prevention is certainly good for haze prevention and it also provides a great market opportunity for haze control. During the period of the "Eleventh Five-year Plan", air purifier sales grew at an annual rate of $27 \%$. According to relevant national plan, schedule and arrangements about the development plan for China's important environmental protection cities after 2014, it is estimated that China's air purifier industry will maintain the rapid growth of $30 \%$ in the four years from 2011 to 2015 [8].

\section{CONCLUSION}

The article analyzes the characteristics, the causes and the hazards of China's hazy weather so as to provide some reference for China's prevention and control of hazy weather. It should be noted that the causes and hazards of hazy weather continuously develop and change with the changes in the environment, so its causes and hazards shall continue to be investigated and revised in future practices.

\section{CONFLICT OF INTEREST}

The author confirms that this article content has no conflict of interest.

\section{ACKNOWLEDGEMENTS}

This work was financially supported by The National Social Science Fund: Research on supply evolution, performance evaluation and optimization strategy of haze control policy in China (14XGL004) and The Provincial Department of education of Humanities and Social Science Fund: Research on the performance management of Energy-saving and Emission-reducing of the Party and government Leader in Counties and Cities-Based on the Gulf of Beibu economic zone development plan (YB2014363).

\section{REFERENCES}

[1] T. Wang, B. Su, and T. Jiang, "Trends of hazy weather against the background of climate change and countermeasures," Environmental Impact Assessment, vol. 1 pp. 15-17, 2014.

[2] T. Zhou, and X. Ru, "Research into the causes of beijing's hazy weather and control measures," Journal of North China Electric Power University (Social Sciences), vol. 4, pp. 12-16. 2012. 
[3] L. Zhang and Y. Pong, "Discussion about the causes of hazy weather in the capital area and countermeasures," Ecological Economy, vol. 9, pp. 172-176, 2014.

[4] H. Xiao, "Analysis of haze causes and countermeasures," Macroeconomic Management, vol. 7, pp. 70-71, 2014.

[5] Q. Liu and P. Li, "Analysis of Causes of Large Scale and Serious Haze and Suggestions for Countermeasures," Journal of Graduate School of Chinese Academy of Social Sciences, vol. 9, pp. 63-68, 2014.
[6] H. Li, "Analysis of the large-scale hazy weather in central and eastern china at the beginning of 2013," Teaching Reference of Middle School Geography, vol. 4, pp. 19-20, 2013.

[7] J. Zhang, J. Sun, and P. Yu, "Analysis of haze causes and reflections," China Emergency Management, vol. 1, pp. 16-21, 2014.

[8] L. Xu, "Air pollution control spawns new investment hotspot in the year of the snake," China Financial and Economic News, vol. 2. p. $28,2013$.

Received: June 10, 2015

Revised: July 29, 2015

Accepted: August 15,2015

(C) Zhou Jingkun; Licensee Bentham Open

This is an open access article licensed under the terms of the Creative Commons Attribution Non-Commercial License (http://creativecommons.org/licenses/by-nc/3.0/) which permits unrestricted, non-commercial use, distribution and reproduction in any medium, provided the work is properly cited. 